\title{
Synthesis and use of copper histidinate in children with Menkes disease in Mexico
}

\section{Andrey Arturo Flores-Pulido, ${ }^{1 *}$ Víctor Manuel Jiménez-Pérez² and Néstor Rodolfo García-Chong ${ }^{1}$}

'Secretaría de Salud, Chiapas High Specialty Regional Center, Pediatric Specialties Hospital, Chiapas; '2Universidad Autónoma de Nuevo León, Faculty of Chemical Sciences, Department of Materials, Nuevo León, Mexico

\begin{abstract}
Menkes disease (MD) is a neurodegenerative and lethal pathology caused by gene mutations of the copper-transporting ATP$7 A$ enzyme; it manifests itself by neurological symptoms and connective tissue changes of varying severity. Timely subcutaneous use of copper histidinate (Cu-His) is determinant for quality of life. We report the first experiences in Mexico on Cu-His synthesis and its safe use in 3 cases where hypocupremia and hypoceruloplasminemia were corroborated. With advice of the Hospital for Sick Children of Toronto Canada, we prepared a $500 \mu \mathrm{g} / \mathrm{mL}$ solution. In all three cases were $250 \mu \mathrm{g}$ of Cu-His applied without relevant undesirable effects for 30 days. Serum copper ( $C u$, expressed in $\mu \mathrm{g} / \mathrm{L}$ ) and ceruloplasmin ( $\mathrm{Cp}$, in $\mathrm{mg} / \mathrm{dL}$ ) were determined: case 1, Cu days 0 and 30,8 and $504 \mu \mathrm{g} / \mathrm{L} ; \mathrm{Cp}$ days 0 and 30,4 and $10.75 \mathrm{mg} / \mathrm{dL}$; case 2, Cu days 0 and 30, < 50 and $502 \mu \mathrm{g} / \mathrm{L} ; \mathrm{Cp}$ days 0 and 30, 2 and $15 \mathrm{mg} / \mathrm{dL}$; case 3, Cu days 0 and 30, 3 and $84.2 \mu \mathrm{g} / \mathrm{L} ; \mathrm{Cp}$ days 0 and 30, 4 and $10.7 \mathrm{mg} / \mathrm{dL}$. In Mexico, it is possible to safely synthesize Cu-His and treat MD, which must be intentionally sought.
\end{abstract}

KEY WORDS: Menkes. Histidinate. Copper. Children.

\section{Introduction}

Menkes disease, OMIM code \# 309400, is a X-linked recessive disorder that is rare (1 in 35000 to 250000 live births), but early lethal and neurodegenerative., It is caused by intragenic mutations or deletions in the gene coding for the ATP7A copper transporter enzyme, which affect multiple enzyme systems (Table 1$)^{3,4}$ and manifest themselves in a clinical spectrum that varies between the severe form (most common) or classic Menkes and occipital horn syndrome (OHS), with manifestations such as severe psychomotor retardation, epileptic encephalopathy, emaciation, failure to thrive, integumentary hypopigmentation, trichodystrophy (pili torti), urocystodystrophy, and osteoporosis, with survival of severe cases generally not beyond the third year of life. ${ }^{3,5}$ For treatment and palliation, copper histidinate (Cu-His) is used as an intervention with potentially significant clinical impact on the central nervous system and quality of life, to the point that in patients who received it early it has prolonged survival to more than 30 years of life in good clinical conditions. ${ }^{6-8}$ We report the first experiences in Mexico in the synthesis of $\mathrm{Cu}-\mathrm{His}$ and the findings with its use in three cases.

\section{Method}

All reagents were produced by Sigma-Aldrich ${ }^{\circledR}$. The $\mathrm{Cu}$-His synthesis was carried out following the Hospital for Sick Children of Toronto Canada instructions (August 2013 version, Department of Pharmacy-Compounding). The copper-derived final product expires 56 days after of being synthesized.
Gac Med Mex. 2019;155:175-179

Contents available at PubMed www.gacetamedicademexico.com 
Table 1. Copper-dependent enzymes in mammals and their probable relationship with Menkes disease

\begin{tabular}{|c|c|c|}
\hline Enzyme & Biological activity & Symptom \\
\hline Cytochrome C oxidase & Cellular respiration & $\begin{array}{l}\text { Central nervous system degeneration, ataxia, muscle weakness, } \\
\text { respiratory failure }\end{array}$ \\
\hline Superoxide dismutase & Free radical sweeping & Central nervous system degeneration \\
\hline Ceruloplasmin & Iron and copper carrier & Anemia \\
\hline Hephaestin & Iron transport & Anemia \\
\hline Tyrosinase & Formation of integumentary pigments & Hypomelanosis \\
\hline Dopamine beta $\mathrm{OH}$-ase & Catecholamine production & Ataxia, hypothermia, hypotension, diarrhea \\
\hline Alpha-amidating peptidyl & Peptide hormones activation & Unspecific \\
\hline Lysyl oxidase & Collagen and elastin cross-links & $\begin{array}{l}\text { Premature membrane rupture, cephalohematoma, abnormal facies, } \\
\text { high-arched palate, emphysema, hernias, urinary bladder diverticula, } \\
\text { arterial aneurisms, joint and skin hyper-laxity, osteoporosis, petechiae, } \\
\text { dehiscent wounds, central nervous system degeneration }\end{array}$ \\
\hline Sulfhydryl oxidase & Keratin crosslinking & Abnormal hair and dry skin \\
\hline
\end{tabular}

The Cu-His magistral preparation $(500 \mu \mathrm{g} / \mathrm{mL})$ was carried out as follows:

- Preparation of $0.2 \mathrm{~N}$ sodium hydroxide solution in $0.9 \%$ sodium chloride solution for injection. Wearing the appropriate protective equipment (safety glasses and gloves), $400 \mathrm{mg}$ of sodium hydroxide were weighed on the analytical balance. Since the substance is supplied as pellets, an adjustment calculation was necessary (e.g.440 mg q.s. $56 \mathrm{~mL}$ ). The pellets were placed in a sterile beaker under the laminar flow hood. $40 \mathrm{~mL}$ of $0.9 \%$ sodium chloride solution for injection were added to dissolve; the preparation was then stirred. Then, q.s $50 \mathrm{~mL}$, with $0.9 \%$ sodium chloride solution for injection was added in a volumetric flask. The milliliters additional to $50 \mathrm{~mL}$ are prepared separately using a syringe and are incorporated to the beaker, where they are mixed.

- Preparation of the Cu-His solution. Wearing appropriate protective equipment (safety glasses and gloves), copper chloride and L-histidine were weighed on the analytical balance. The flask was weighed and quickly returned to the desiccator (copper chloride is hygroscopic). Both powders were placed in the beaker and dissolved in approximately $185 \mathrm{~mL} 0.9 \%$ sodium chloride solution for injection; the preparation was gently stirred only to dissolve it (the product is sensitive to oxygen). After standardizing, the electrode (between $\mathrm{pH} 4$ and 7) was submerged several times in $99 \%$ alcohol to clean it; then it was carefully rinsed. The solution was adjusted to a $\mathrm{pH}$ of 7.38 to 7.40 , using $0.2 \mathrm{~N}$ of the sodium hydroxide solution; the $\mathrm{pH}$ of the solution was determined. Approximately $14 \mathrm{~mL}$ plus 10 to 13 drops were taken (depending on $\mathrm{NaOH}$ potency more or less were used); after each addition they were mixed well. pH was continuously monitored. Once close to the indicated $\mathrm{pH}$ (6.9 to 7.0), half a drop was added and slowly stirred. Upon reaching the indicated $\mathrm{pH}$, the electrodes were cleaned with sterile water and the solution was transferred to a volumetric flask. The volume was adjusted to $200 \mathrm{~mL}$ with $0.9 \%$ sodium chloride solution for injection. The $\mathrm{pH}$ was measured again to ensure it remained within range (sometimes, extra $\mathrm{NaOH}$ drops may be needed). The solution was transferred to a beaker. Copper-histidine solution was drawn in a $20 \mathrm{~mL}$ syringe and $3 \mathrm{~mL}$ of the solution were filtered using a 0.22 micron disc filter into either 5 or $10-\mathrm{mL}$ vials.

It is important to consider some technical specifications:

- The flasks and beakers used in the preparation of the copper-histidine solution should be covered with aluminum because the product is highly sensitive to light. The hood light should be off during preparation. If copper chloride turns blue/ green, it is essential to check with the pharmacist prior to its use.

- Once the first vial is prepared, it must be sent to have the copper level measured. 


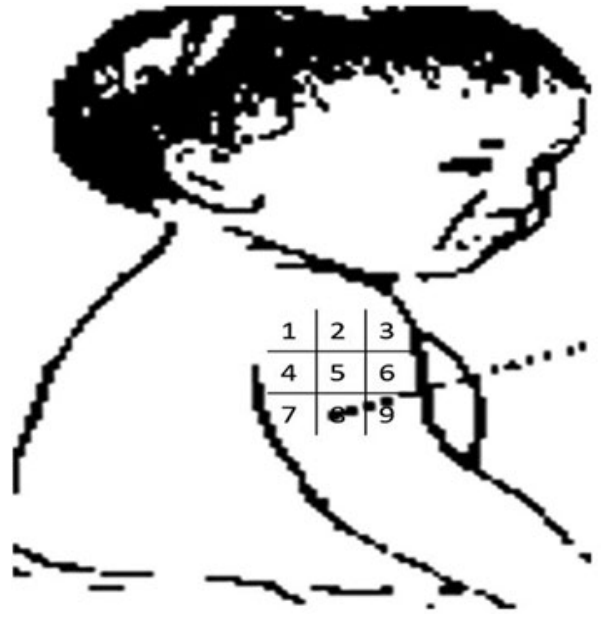

Figure 1. Cu-His subcutaneous administration quadrants (right and left arm proximal third posterolateral aspect). Source: Reference 8 image recreation.

- The product should remain aqua blue in color. If it is darkened to blue-greenish it means that it is degrading.

- Once finished, the product should not be subjected to impact or shaken.

To avoid degeneration by photic or thermal exposure, $2 \mathrm{~mL}$ falcon-type vials with amber color were used and transported on a support base to keep them vertical in containers, whose internal temperature should range from 4 to $10^{\circ} \mathrm{C}$

For its unit dispensation it is suggested to load within the area of pharmaceutical services within minutes prior to its administration, in a room with dimmed light and regulated temperature and a laminar flow hood in a $1 \mathrm{~mL}$ syringe with a $27 \mathrm{G} \times 13 \mathrm{~mm}$ needle, checking for appropriate coloration and protecting the injection device as soon as possible with dark plastic.

For administration, the deltoid region of both arms was used, divided into nine quadrants to order daily application (Figure 1). ${ }^{7}$ The injection must be administered by the subcutaneous route. The recommended standard dose is $250 \mu \mathrm{g} /$ dose $(0.5 \mathrm{~mL})$ every 24 hours. ${ }^{2,3,4}$

\section{Results}

The solution resulting from the preparation-clear, aqua blue, photosensitive and thermosensitive (Figure 2) was applied without significant undesirable effects related to the site of subcutaneous (deltoid) administration, or relevant systemic effects during patient follow-up. During the first 30 days, daily subcutaneous administration (after informed consent is obtained) of $\mathrm{Cu}$-His $250 \mu \mathrm{g}$ in patients with Menkes disease generates

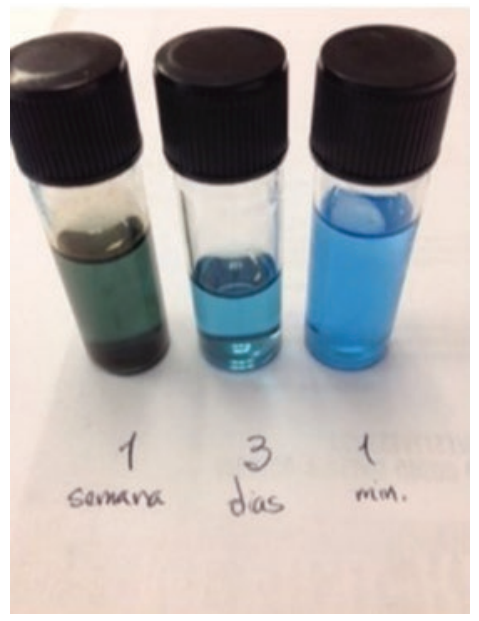

Figure 2. Solution appearance. Source: Picture taken at Universidad Autónoma de Nuevo León Faculty of Chemistry laboratory of materials with the first batch of synthesized vials.

changes in serum copper determinations $(\mathrm{Cu}$, reference level 700 to $1750 \mu \mathrm{g} / \mathrm{L})$ and ceruloplasmin (CP, reference level 22 to $58 \mathrm{mg} / \mathrm{dL}$ ) (Figures 3 and 4).

Case 1 was detected at 12 months of age, case 2 at 36 months of age and case 3 at four months of age. In all cases, attenuation in the number and duration of infantile spasms was observed, as well as improvement in reactivity and sleep-alertness alternation. Only case 3 had integumentary changes, even with $\mathrm{Cu}$ and $\mathrm{CP}$ levels lower than reference levels. At the time of this report, spectroscopic measurement and $\beta$-microglobulin behavior monitoring was ongoing as follow-up of the tubular function.

\section{Discussion}

$\mathrm{Cu}$-His is an endogenous or synthetic molecule that reinforces intracellular uptake of copper and at the same time is a modulator or buffer of copper exchange between the cell and albumin, which regulates its bioavailability. ${ }^{2,9}$

In Menkes disease, $\mathrm{Cu}$ and CP serum levels are negligible, primarily due to an impairment of intestinal absorptive capacity related to ATP7A dysfunction, with supplementary treatment therefore being focused on replacing this element. Once cupremia is recovered, ceruloplasminemia restitution is induced, which assures its efficient delivery to the cells. However, once in the plasmatic compartment, copper high affinity for albumin must be evaded, which reduces its bioavailability. This is where the value of multitasking of molecules such as $\mathrm{Cu}$-His lies, since other molecules such as copper chloride, copper sulfate, copper ethylenediaminetetraacetic 


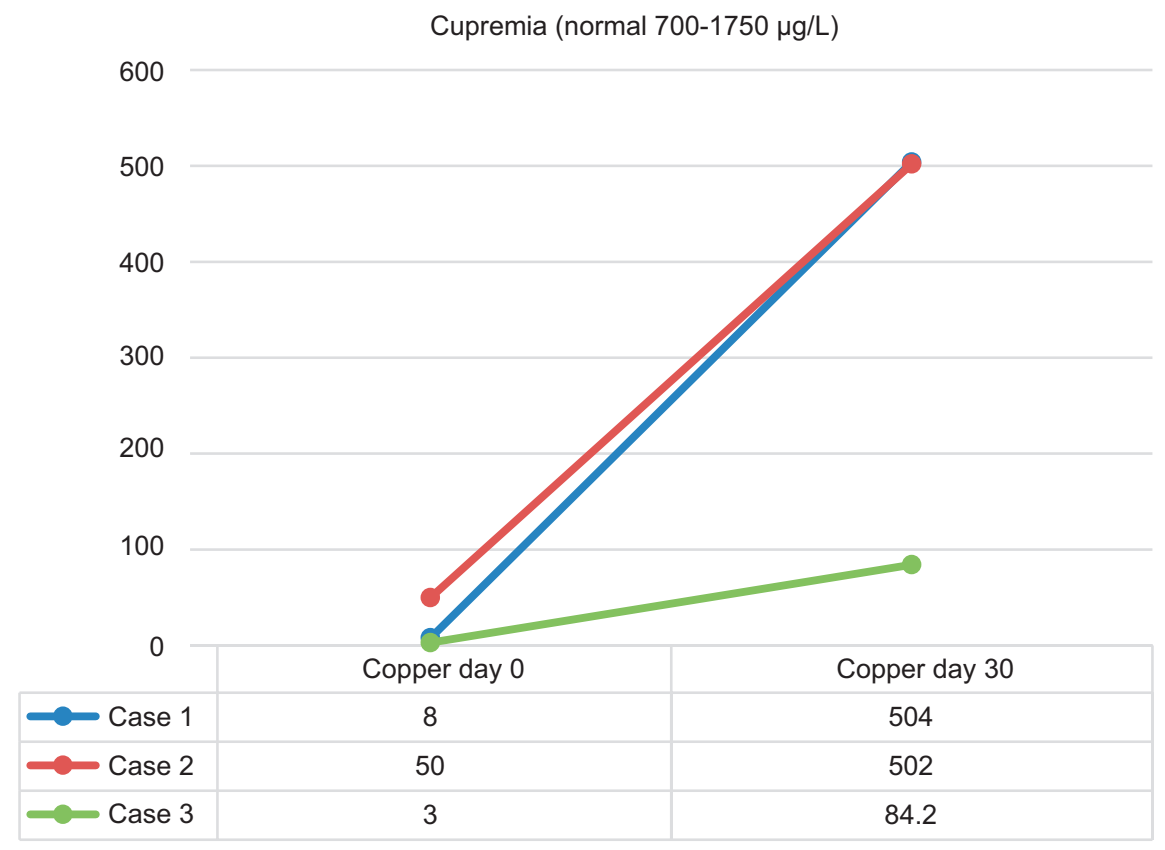

Figure 3. Cupremia after 30 days of $\mathrm{Cu}$-His use in all three cases.

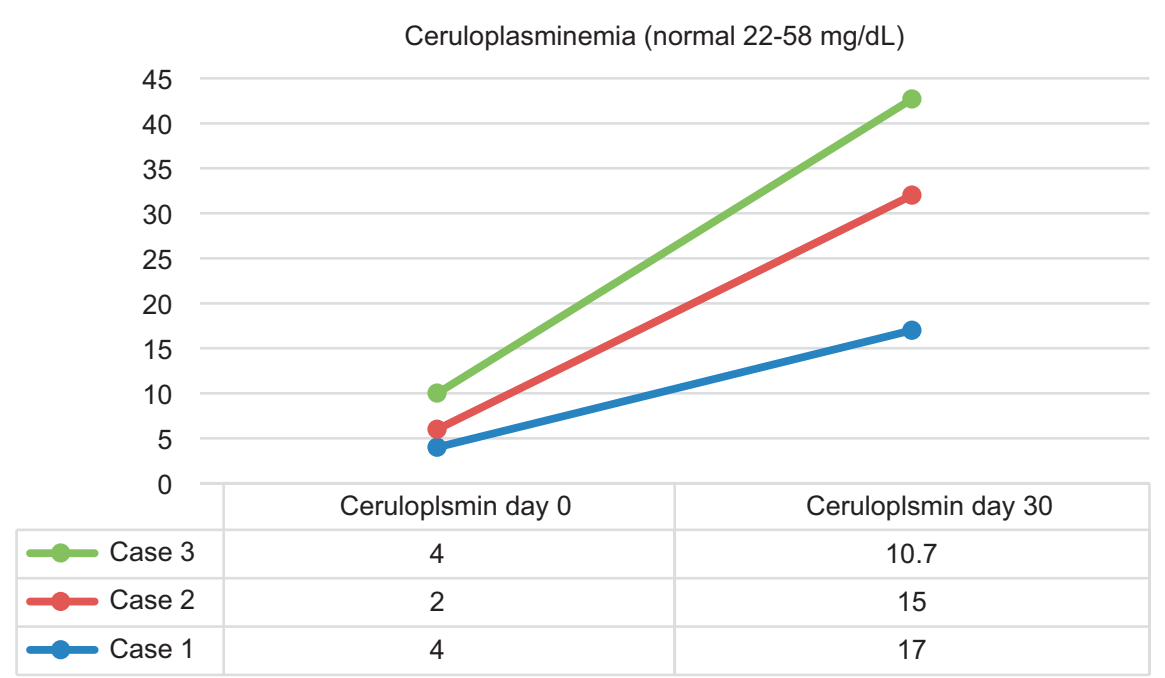

Figure 4. Ceruloplasminemia after 30 days of $\mathrm{Cu}$-His use in all three cases.

acid and cupric albumin have failed to show sufficient clinical impact in comparison with with $\mathrm{Cu}-\mathrm{His} .^{9-12}$

The recommendation is to use $\mathrm{Cu}$-His in order to improve $\mathrm{Cu}$ bioavailability in copper-dependent enzymatic systems through the subcutaneous route, evading the enteral barrier defect and facilitating and capturing copper transfer from copper albumin to improve its bioavailability. This has been established according to several cases of early detection in the range from zero to seven months of age, where neurological evolution prognosis drastically changes, especially if
$\mathrm{Cu}$-His is administered within the first two months of life. ${ }^{3,6,9-13}$ Our cases were 12 and 36 and 4 months of age, with classic Menkes disease evolution and their main problem was nutritional status and refractory epilepsy. There is sparse information available on CuHis late initiation, which cannot be contrasted with early-initiation chronic use in most reported series (during the first three years of life)., ${ }^{7,13}$

The decision to develop the $\mathrm{Cu}$-His synthesis in Mexico - which had not been possible due to the instability of this substance in an aqueous state and 
because the logistical network to allow its safe availability had not been established - was motivated by the possibility of drastically modifying the natural history of future cases and of having a potentially beneficial late intervention, although of uncertain effect, which requires close monitoring.

In counting the obstacles, performing atomic absorption tests and sterility are the procedural steps that require more resources and precision, despite of which they were optimally performed.

In spite of Cu-His late initiation, plasma and clinical improvement changes were observed, and its use will therefore continue with the monitoring of findings and their comparison with those of other series.

We believe that in Mexico it is possible to collaboratively and safely synthesize $\mathrm{Cu}$-His and early accessing to Menkes disease treatment, which involves a deliberate and systematic search of cases throughout the national system, since many subjects die due of the lack of timely detection.

\section{Acknowledgements}

With the generous support of doctors Sarkar and Walsh from the Hospital for Sick Children of Toronto, Canada, and of Dr. Víctor Manuel Jiménez of the Faculty of Chemical Sciences, Universidad Autónoma de Nuevo León, synthesizing, securing, dispensing and safely administering $\mathrm{Cu}$-His at the Chiapas High
Specialty Regional Center has been possible, as well as remotely sharing it thanks to the logistical support of the clinical laboratory, pharmaceutical services and operation management. This work is in honor to the battle faced by Harold, Álan, Gabriel and their families against Menkes disease.

\section{References}

1. Carbajal-Rodríguez L, Belmont-Martínez L, González-Del Ángel A, Delgado-Falcón J, Durán-C, Rodríguez-Herrera R, et al. Síndrome de Menkes. Bol Med Hosp Infan Mex. 2002;59:365-371.

2. Christodoulou J, Danks D, Sarkar B, Baerlocher K, Casey R, Horn N, et al. Early treatment of Menkes disease with parenteral cooper-histidine: long term follow-up of four treated patients. Am J Med Genet. 1998; 76:154-164.

3. Deschamps P, Kulkarni P, Gautam-Basak M, Sarkar B. The saga of copper (II)-L histidine. Coord Chem Rev. 2005;249:895-909.

4. Ojha R, Prasad AN. Menkes disease: what a multidisciplinary approach can do. J Multidiscip Healthc. 2016;9:371-385

5. Garnica A, Chan WY, Rennert O. Copper-histidine treatment of Menkes disease. J Pediatr. 1994;125:336-338.

6. León-García, Dávila-Gutiérrez. Estado actual de la enfermedad de Menkes en México. Salud Publica Mex. 2012;54:103-104.

7. Menkes JH, Alter M, Steigleder GK, Weakley DR, Sung JH. A sex-linked recessive disorder with retardation of growth, peculiar hair, and focal cerebral and cerebellar degeneration. Pediatrics. 1962;29:761-779.

8. Vía de administración subcutánea en lactantes e infantes. Disponible en: https://image.slidesharecdn.com/1-tecnicasdeaplicacion-1302011 20246-phpapp01/95/1tcnicas-de-aplicacin-vacunas-13-638.jpg?$\mathrm{cb}=1359720489$

9. Sarkar B, Lingertat-Walsh K, Clarke JTR. Cooper histidine therapy for Menkes disease. J Pediatr. 1993;123:828-830.

10. Tümer Z, Møller LB. Menkes disease. Eur J Hum Genet. 2010;18:511-518.

11. Tümer Z, Chirstodoulou J, Clarke JTR, Sarkar B, Horn N. Early cooper histidine treatment for Menkes disease. Nat Genet. 1996:12:11-13.

12. Kaler SG, Holmes CS, Goldstein DS, Tang J, Gosdwin S, Donsante A, et al. Neonatal diagnosis and treatment of Menkes disease. N Eng $J$ Med. 2008;358:605-614.

13. Sheela SR, Latha M, Liu P, Lem K, Kaler SG. Copper-replacement treatment for symptomatic Menkes disease: ethical considerations. Clin Genet. 2005;68:278-283 